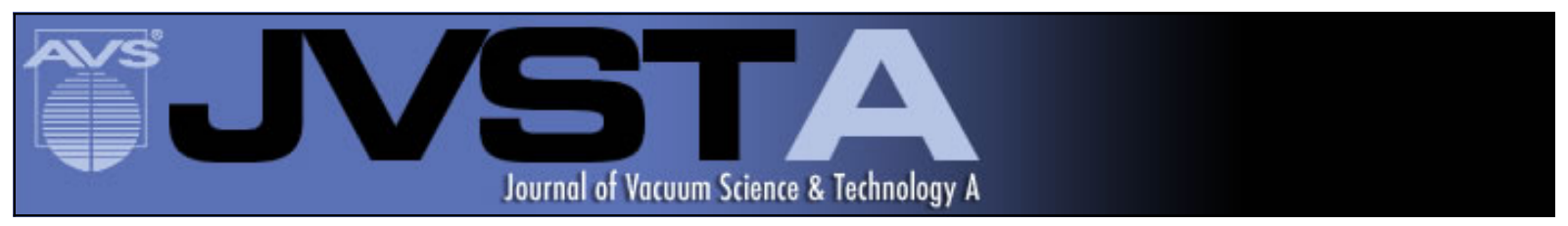

\title{
Etching silicon by SF 6 in a continuous and pulsed power helicon reactor
}

A. Herrick, A. J. Perry, and R. W. Boswell

Citation: Journal of Vacuum Science \& Technology A 21, 955 (2003); doi: 10.1116/1.1575215

View online: http://dx.doi.org/10.1116/1.1575215

View Table of Contents: http://scitation.aip.org/content/avs/journal/jvsta/21/4?ver=pdfcov

Published by the AVS: Science \& Technology of Materials, Interfaces, and Processing

\section{Articles you may be interested in}

High rate deep Si etching for through-silicon via applications

J. Vac. Sci. Technol. A 29, 021009 (2011); 10.1116/1.3543635

An interatomic potential model for molecular dynamics simulation of silicon etching by $\mathrm{Br}+$-containing plasmas J. Appl. Phys. 104, 073302 (2008); 10.1063/1.2990070

Topographic and kinetic effects of the SF 6 / O 2 rate during a cryogenic etching process of silicon

J. Vac. Sci. Technol. B 22, 1912 (2004); 10.1116/1.1767825

Fluorocarbon plasma etching of silicon: Factors controlling etch rate

J. Appl. Phys. 96, 65 (2004); 10.1063/1.1736321

Comparison of negative-ion and positive-ion-assisted etching of silicon

Appl. Phys. Lett. 79, 1769 (2001); 10.1063/1.1400765

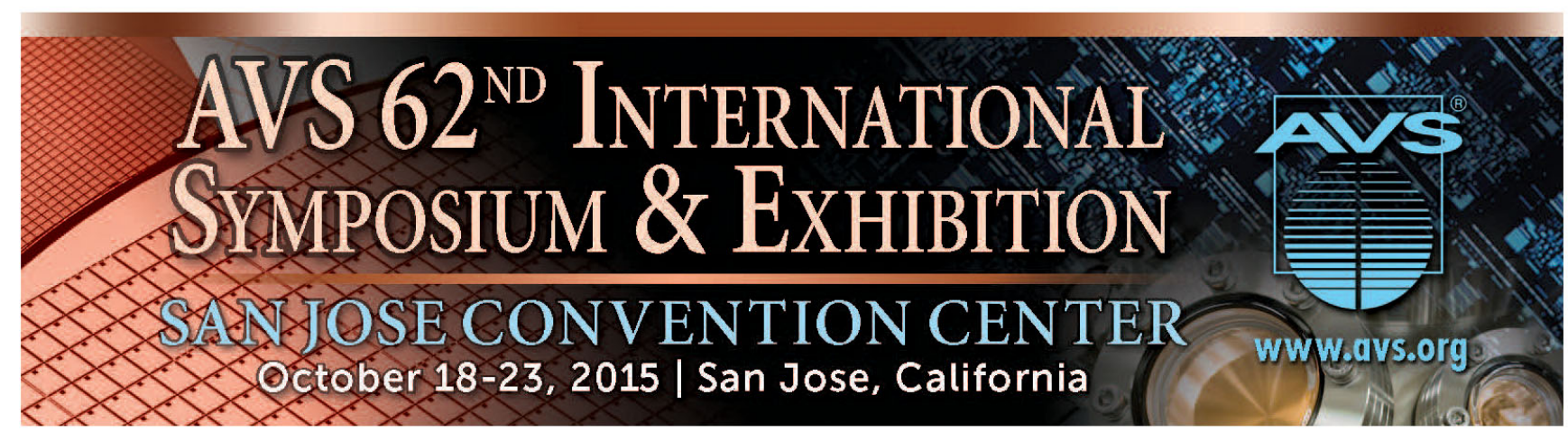




\title{
Etching silicon by $\mathrm{SF}_{6}$ in a continuous and pulsed power helicon reactor
}

\author{
A. Herrick, A. J. Perry, and R. W. Boswell ${ }^{\mathrm{a})}$ \\ Space Plasma and Plasma Processing Group, PRL/RSPhysSE, ANU, Canberra, 0200, Australia
}

(Received 11 July 2002; accepted 24 March 2003; published 27 May 2003)

\begin{abstract}
The etch rate of silicon by $\mathrm{SF}_{6}$ in a helicon reactor has been measured along with simultaneous actinometric measurements of the concentration of atomic fluorine in the gas phase for a variety of gas flow rates resulting in pressures in the mTorr range. A bias rf power was applied to the substrate to investigate the effect of ion energy on the etch rate. The etch rate was found to be proportional to the fluorine concentration and independent of the bias for the higher gas flow rates. However, at lower flow rates, the situation was more complicated and no simple model can explain the measurements. Measurements of the etch rate were also made in the afterglow of a repetitively pulsed discharge so that the directed ion energy would be reduced to the thermal motion after the rapid collapse of the plasma potential. A simple model was developed to explain the temporal etching phenomena in terms of the lifetime of the atomic fluorine. (C) 2003 American Vacuum Society. [DOI: 10.1116/1.1575215]
\end{abstract}

\section{INTRODUCTION}

Experiments in etching of silicon with $\mathrm{SF}_{6}$ using a pulsed rf power supply have been carried out previously in our laboratory but in a small diameter glass tube ${ }^{1}$ that had little resemblance to modern etching systems. Subsequent measurements taken here and elsewhere ${ }^{2,3}$ showed that for these reactors, the etch rate scaled with the measured fluorine concentration which has been identified ${ }^{4}$ as being a result of processing in a fluorine limited regime. The latter authors also found another regime where the ion bombardment played a major role. The original pulsed etching experiments showed that it was necessary to invoke etching in the afterglow of the plasma to explain the measured etch rates. This was curious as it was commonly assumed that ions were necessary to "activate" the etching process, at least in the prepared system of an initially clean silicon surface covered with fluorine by passing $\mathrm{XeF}_{2}$ gas over it. ${ }^{5}$

When an electronegative plasma is pulsed off, the fast electrons move to the walls and are not replaced and slower electrons are lost by attachment in the gas phase, both processes being very fast, leaving a plasma consisting of positive and negative ions at a very low potential. An "equilibrium" decay is reached after all the ballistic ions, which were in the process of being accelerated in the presheaths before the plasma was pulsed off, arrive at the walls, a process which typically takes between 50 and $100 \mu$ s.

In these afterglow conditions we can safely say that there is no energetic ion bombardment of any surface immersed in the plasma. Of course, there is the internal energy of various species such as metastables and vibrational and rotational energy of molecular species which may need to be considered in the overall picture of the etching phenomena. These species will contribute to the etching both during the on period of the plasma and after the plasma is extinguished. The importance of their role is rather small in this experiment as will be shown by the actinometric measurements of the fluo-

\footnotetext{
a) Author to whom correspondence should be addressed; electronic mail: rod.boswell@anu.edu.au
}

rine species and the correlation with the etch rates. Our interest is to verify the earlier measurements of etching continuing in the afterglow with a time scale longer than that of the plasma lifetime.

The initial experiments were carried out to determine the basic etch characteristics of the reactor using a continuous plasma. Having determined the steady state conditions, the rf power supply was pulsed and the experiments repeated.

\section{EXPERIMENTAL APPARATUS}

A schematic diagram of the helicon processing reactor is shown in Fig. 1. It consisted of two coaxial cylinders joined together; the upper cylinder is the glass source tube which is $25 \mathrm{~cm}$ in length and $15 \mathrm{~cm}$ in diameter; the lower cylinder is the diffusion chamber and houses the wafer stage; it is made from aluminum and is $30 \mathrm{~cm}$ long and $30 \mathrm{~cm}$ in diameter. Solenoids surround both cylinders and created an axial magnetic field of $100 \mathrm{G}$ in the source decreasing to $60 \mathrm{G}$ in the diffusion chamber. The expanding field allowed a more uniform etch of about $5 \%$ to be achieved on the 4 in. wafer. A separate load lock chamber allowed the loading of wafers into the reactor without having to bring it up to atmospheric pressure.

The wafer table was water cooled, with 2.5 Torr of helium in the $300 \mu \mathrm{m}$ gap between the wafer and the table providing the heat exchange, and could be biased to a negative potential by applying rf power at $13.56 \mathrm{MHz}$ to the substrate holder via a matching network containing a bias capacitor.

Around the source tube was placed a double saddle fieldtype helicon antenna ${ }^{6}$ which was coupled to a $13.56 \mathrm{MHz}$ rf source via a matching network; it was phase locked to the rf power supplied to the wafer. Source powers of up to $1.5 \mathrm{~kW}$ were used routinely, while the bias power ranged from 5 to $50 \mathrm{~W}$. The gas flow was controlled with $100 \mathrm{sccm}$ mass flow controllers $(\mathrm{MFCs})(\mathrm{sccm}=$ standard cubic centimeters per minute), and the reactor was pumped by a $400 \mathrm{l} / \mathrm{s}$ turbomolecular pump and rotary combination. A typical base pressure for the reactor was $1.80 \times 10^{-5}$ Torr although the true 


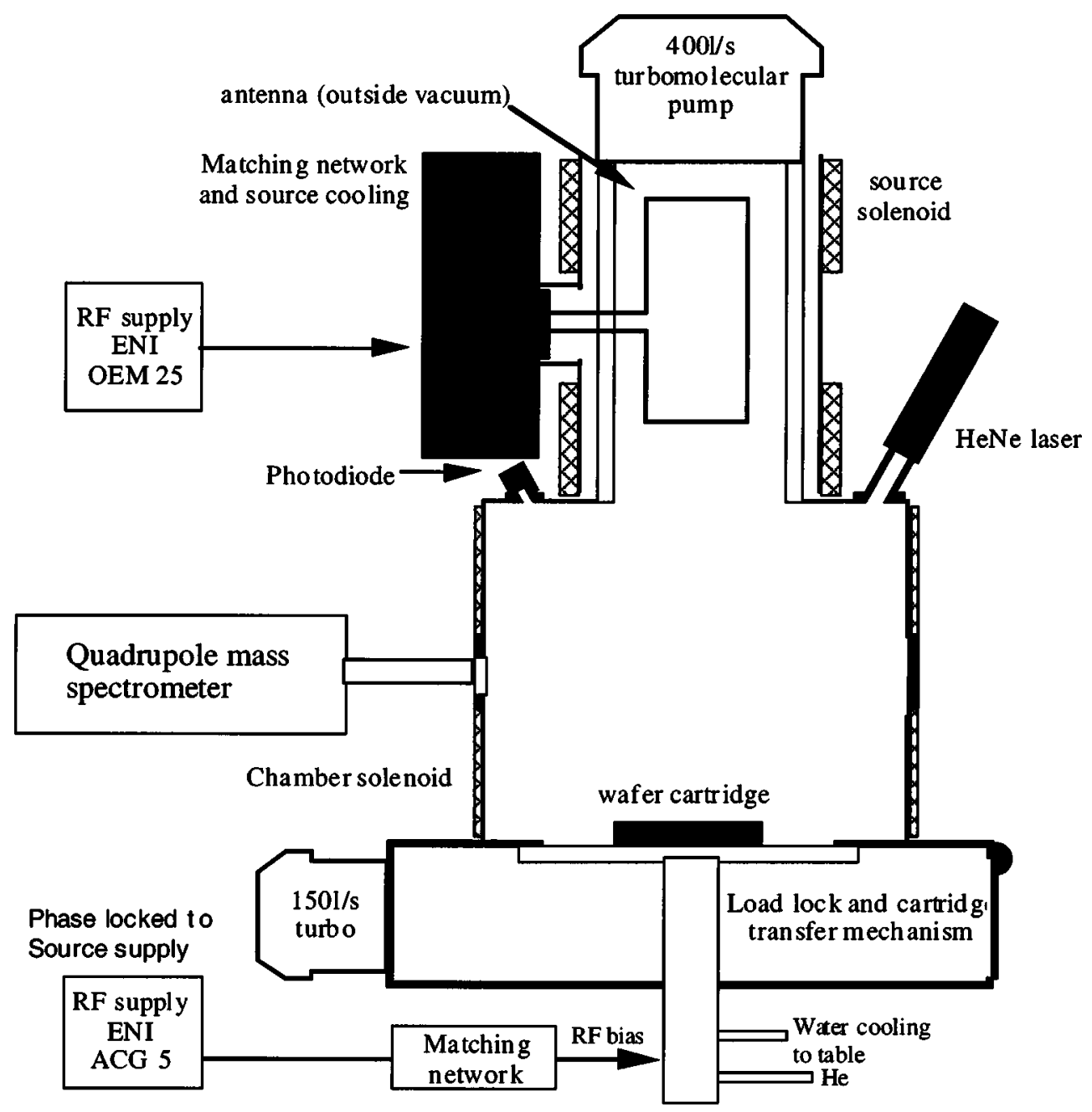

FIG. 1. Schematic diagram of the helicon processing reactor.

base pressure was about five times lower than this but a nitrogen purge was used on the pump bearings to protect them from fluorine.

The electronic MFCs were inadequate for controlling the extremely low flows of argon required for actinometry because they were affected by rf noise from the wafer table. Hence, a needle valve was used which was not subject to $\mathrm{rf}$ noise but needed to be calibrated at the beginning of each run. It was set using a capacitance manometer (which provided absolute pressure measurements) allowing the argon pressure of 0.1 mTorr to be set to within $5 \%$.

\section{ETCH RATE MEASUREMENTS}

The etch rate was measured in situ using optical interferometry in two ways. The first used a HeNe laser as shown in Fig. 1 which was oriented to give a reflected beam which impinged on the photodiode. The wafer samples consisted of crystalline silicon on which had been deposited parallel lines of chromium $3 \mu \mathrm{m}$ wide with a $7 \mu \mathrm{m}$ spacing. Light reflected from the mask and substrate interfered, and as the etch profile deepened the two beams moved in and out of phase and interference fringes were produced. This method assumed that the mask etch rate was negligible; an assumption justified since a typical etch rate for chrome is of the order of a few nanomers per minute. A typical sample size was $2 \mathrm{~cm}^{2}$, the samples being affixed to a standard $4 \mathrm{in}$. backing wafer using silver loaded paint which ensured good electrical and thermal contact.

The second method used an entire unmasked 4 in. wafer, which had been polished on both sides, as the sample. A HeNe laser was used but with an IR wavelength $(\lambda=1.523$ $\mu \mathrm{m}$ ); silicon is transparent to infrared radiation (refractive index $=3.4803$ ) which was reflected off the top and bottom surfaces of the wafer. It was then possible to etch for many tens of microns on a single sample without needing to change the wafer. Care had to be taken because the refractive index was also temperature dependent; thus when a bias was applied fringes were produced which were not caused by etching but by the ions depositing power in the wafer and thus heating it; this transient behavior was allowed to decay before a measurement was made. Interferometry gave an accurate measurement of the etch rate because the dimensions of the reactor were accurately known and the angular dependence appeared as the cosine of a small angle, further reduc- 
ing the error leading to errors of roughly $0.5 \%$.

A pulsed plasma presented problems as it was not possible to directly measure the etch rate during the "on" part of the pulse, because a typical time between intensity maxima of the interference fringes was several minutes, hence only the average etch rate could be measured.

\section{ION ENERGY AND BIAS POWER}

The power applied to the wafer was not equal to the power dissipated by the ion bombardment, as there were losses in the sample holder (which were minimized by making it out of ceramic) and resistive losses in the connections. The true power being applied to the wafer was the power measured at a defined current with a plasma minus the power that was measured at the same current, but with no plasma. When bias power is quoted henceforward, it will have been corrected in this way. The measured bias voltage was found to increase linearly with the bias power showing that current to the biased substrate was constant and that the bias did not produce its own plasma.

\section{ACTINOMETRY}

For continuous measurements of the fluorine concentration in the plasma a Monolight 6602 optical spectrum analyzer was used which tended to produce quite a lot of scatter in measurements since it was scanning through the desired spectrum at a frequency of $1 \mathrm{~Hz}$. This was minimized by averaging the signal over a period of 20-30 s. The intensity of the F line $(703.7 \mathrm{~nm})$ and the Ar line $(750.4 \mathrm{~nm})$ was then obtained and transferred to a PC for analysis by actinometry ${ }^{7}$ which allowed the fluorine concentration to be obtained from the relation

$$
n_{\mathrm{F}}=K n_{\mathrm{AR}} \frac{I_{\mathrm{F}}}{I_{\mathrm{AR}}},
$$

where $I_{\mathrm{F}}$ and $I_{\mathrm{AR}}$ are the intensities of the fluorine and argon lines, respectively. The value used for $K$ was 0.44 and was obtained from Ding et $a l .{ }^{4}$ but it is not universally agreed upon due to uncertainties in the cross sectional data; in a later article Jeng et $a .^{8}$ used the value 0.56 . Due to this uncertainty, the absolute fluorine measurements were subject to a possible error of $20 \%$ or so.

The measurements of emissions from a pulsed plasma were made with a SPEX 500M monochromator and the data transferred to a PC for processing. A study of this time resolved actinometry has been conducted by Hancock, Sucksmith, and Toogood ${ }^{9}$ who used the technique to monitor the fluorine and $\mathrm{CF}_{2}$ concentrations in a parallel plate device. Both devices recorded intensities through an optical fiber which was positioned in front of a fused silica window in the side of the diffusion chamber.

\section{PULSING THE rf HELICON POWER}

This was done using a pulse generator connected to the rf generator. Although the pulse generator has a rise time of a few nanoseconds, the rf generator had a rise and fall time of
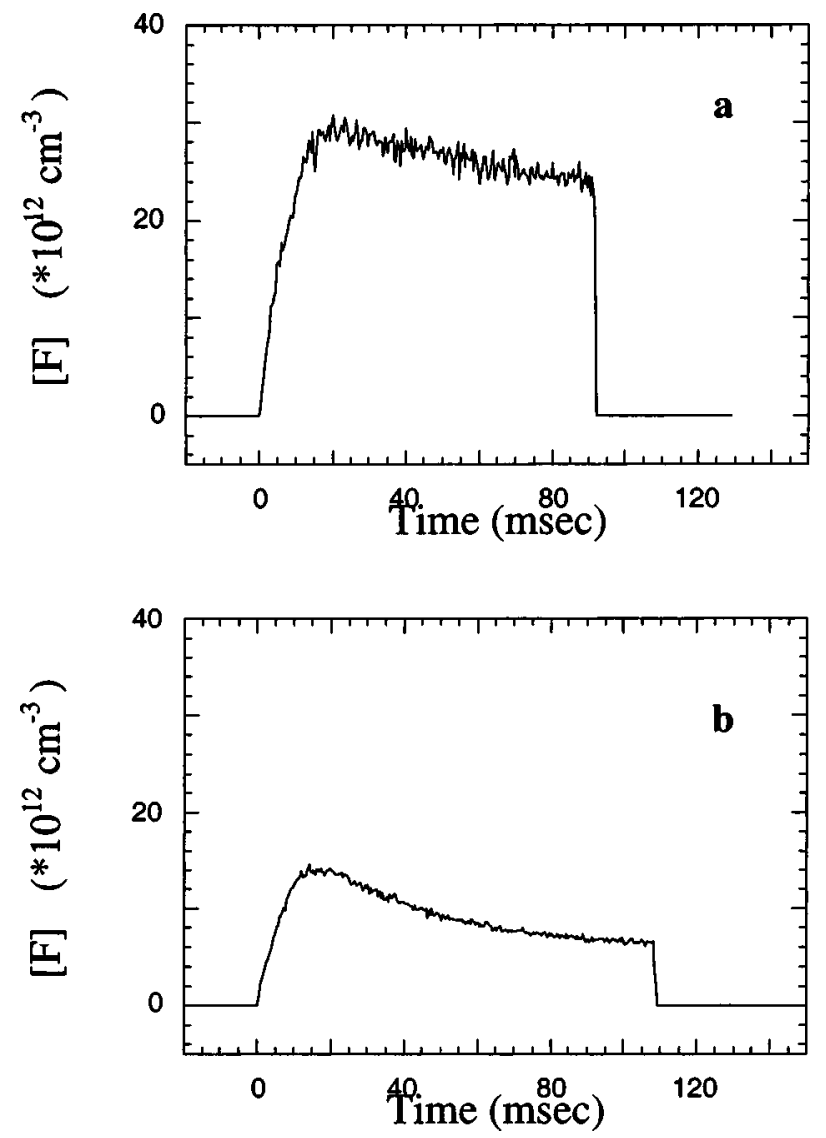

FIG. 2. Fluorine concentration as a function of time with stainless steel wafer (a) and silicon wafer (b).

around $70 \mu$ s mainly as a result of its control circuitry. Hence we do not concern ourselves with the processes occurring on these short time scales (interesting though they may be) and restrict our investigation to the millisecond time scale.

\section{PRELIMINARY RESULTS}

A pulse of about $100 \mathrm{~ms}$ was applied to the plasma with a flow of $16.8 \mathrm{sccm}$ of $\mathrm{SF}_{6}$ and $1200 \mathrm{~W}$ of $\mathrm{rf}$ helicon power to investigate the rise and fall times of the fluorine and to determine whether a 4 in. silicon wafer would "load" the system. In Fig. 2(a) the fluorine concentration is shown using a wafer of stainless steel whereas in Fig. 2(b) the wafer is clean silicon. In both cases the rise time of the fluorine concentration was the same (roughly $10 \mathrm{~ms}$ and is probably due to the lifetime of the fluorine as discussed later in this article), however, with the silicon wafer absent, the peak fluorine concentration was many times that measured with the silicon wafer. The fall time of the optical emission is very fast and simply reflects the rapid loss of fast electrons when the $\mathrm{rf}$ is not present. Clearly there was significant consumption of fluorine by the etch reaction suggestion that the etch rate should be limited by the fluorine concentration. Time constants for various processes: 

Ambipolar diffusion
$\sim 70 \mu \mathrm{s}$
Free diffusion
$\sim 500 \mu \mathrm{s}$
rf generator time constant
$70-100 \mu \mathrm{s}$
Gas heating
Gas cooling
$\sim 500 \mu \mathrm{s}$ for free diffusion
if thermal accommodation on the walls then $500 \mu \mathrm{s}$
$\begin{array}{ll}\text { Electron cooling in afterglow } & \sim 70 \mu \mathrm{s} \\ \text { Stable plasma density } & \sim 1 \mathrm{~ms}\end{array}$

It is also useful to discuss the residence time of species which is defined as

$$
\begin{aligned}
\tau & =\text { volume } / \text { pumping rate } \\
& =2.1 \times 10^{4} / 2 \times 10^{5} \\
& =100 \mathrm{~ms} .
\end{aligned}
$$

This calculation uses the pumping rate of the turbomolecular pump which we measure to have an effective pumping speed of $2001 \mathrm{~s}^{-1}$ and hence assumes that the species being pumped are not consumed elsewhere in the reactor.

For the experiment described here the fluorine is clearly consumed very effectively by the silicon wafer which represents a "black hole" of $10 \mathrm{~cm}$ diameter. For this case, the effective pumping rate of fluorine for the experiments at 8 $\mathrm{sccm}$ and an etch rate of $650 \mathrm{~nm} \mathrm{~min}{ }^{-1}$, we estimate in Sec. IX that the total pumping rate of fluorine is equivalent to about ten times that of the turbo-molecular pump, resulting in a residence time of around $10 \mathrm{~ms}$.

\section{ETCHING WITH CONTINUOUS PLASMAS}

Before presenting the pulsed experiments, the etch rate dependence on bias power, gas flow rate, and source power will be examined, noting that at a constant source power, changing the bias power changes only the ion energy. Three flows were chosen that produced pressures approximately in the ratio 1:2:3 allowing a wide range of conditions to be examined.

Figures 3, 4, and 5 present the etch rate (a) and the fluorine density (b) dependencies on bias power for flow rates of 8.0, 16.8, and $25.0 \mathrm{sccm}$ of $\mathrm{SF}_{6}$, corresponding to pressures of $0.8,1.5$, and 2.1 mTorr. However, the pressure can vary with the rf input power which changes the dissociation rate and a variety of other parameters so henceforth only the gas flow rates will be used. Each set of results was taken for $\mathrm{rf}$ helicon powers of 430, 800, and $1200 \mathrm{~W}$ using the double polished wafer/IR laser method as the use of patterned wafers was found to be inappropriate due to aspect ratio dependent etching effects. ${ }^{10,11}$

\section{A. High flow rate regime}

The results for $\mathrm{SF}_{6}$ flows of 16.8 and $25.0 \mathrm{sccm}$ were easy to understand; the etch rate was proportional to the fluorine concentration and was essentially independent of ion energy. This was to be expected, since Fig. 2 showed a strong consumption of fluorine by the etch reaction and so it was logical to deduce that the fluorine concentration would limit the etch rate. Petit and Pelletier ${ }^{2}$ have previously observed this
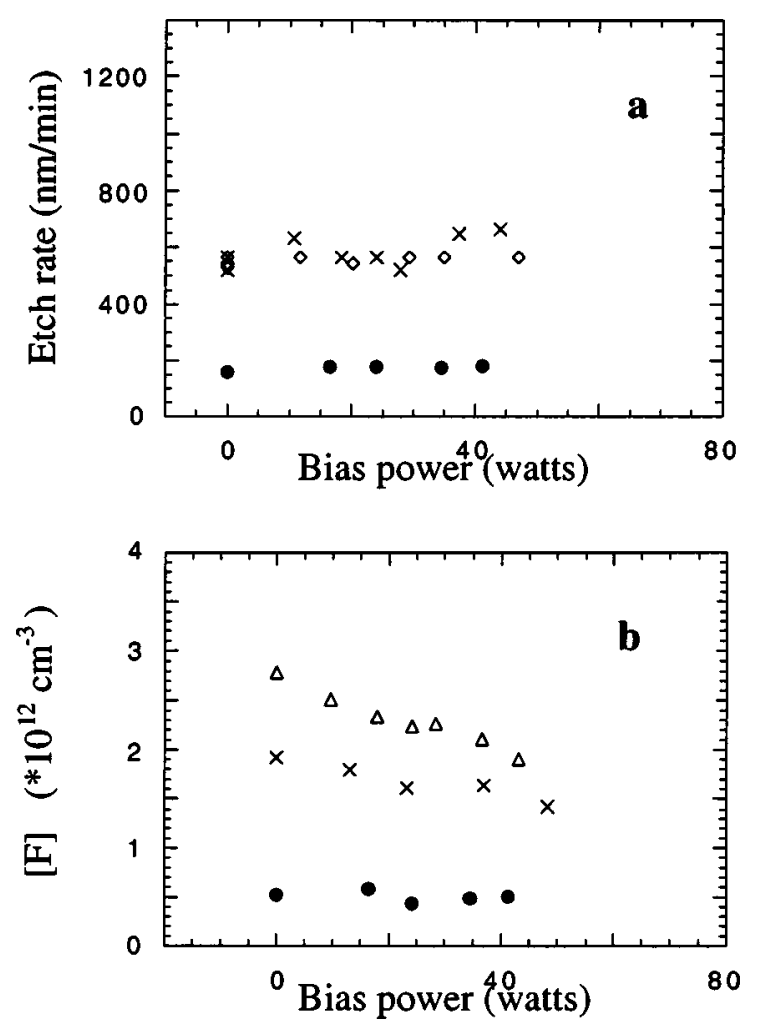

FIG. 3. Etch rate (a) and fluorine concentration (b) as a function of bias power for helicon powers of $430 \mathrm{~W}$ (filled circles), $800 \mathrm{~W}$ (crosses), and $1200 \mathrm{~W}$ [open lozenges in (a) and open triangles in (b)] for a flow of $8 \mathrm{sccm}$ $\mathrm{SF}_{6}$.

behavior in an electron cyclotron resonance plasma and found that the etch rate scaled with the $\mathrm{SF}_{6}$ flow rate but not with the ion energy or ion current density. Not surprisingly (given that the experiments were conducted on the same type of reactor in the Southern Hemisphere), the results also agree with those obtained by Perry and Boswell, ${ }^{3}$ who found the etch rate increased with etch gas pressure (i.e., fluorine concentration) but was essentially independent of the ion energy.

\section{B. Low flow rate regime}

At a flow of $8 \mathrm{sccm}$, Fig. 3(a) shows no significant rise in etch rate as the source power is increased from 800 to 1200 W, while Fig. 3(b) displays a clear increase in fluorine concentration for all bias powers.

One would be lead to suggest that another limiting factor was now playing a role such as Ding' $s^{4}$ suggestion of an ion energy flux limited regime. However, for the plasma studied here, the 800 and $1200 \mathrm{~W}$ etch rates showed no significant dependence on the bias power $E_{i} J_{i}$ applied to the wafer showing that the additional ion energy was not affecting the etch process.

The fact that the etch rate was independent of fluorine concentration was especially surprising because these results were obtained at a low flow, where the available fluorine was scarce and the etch rate was expected to be limited by the fluorine concentration. 

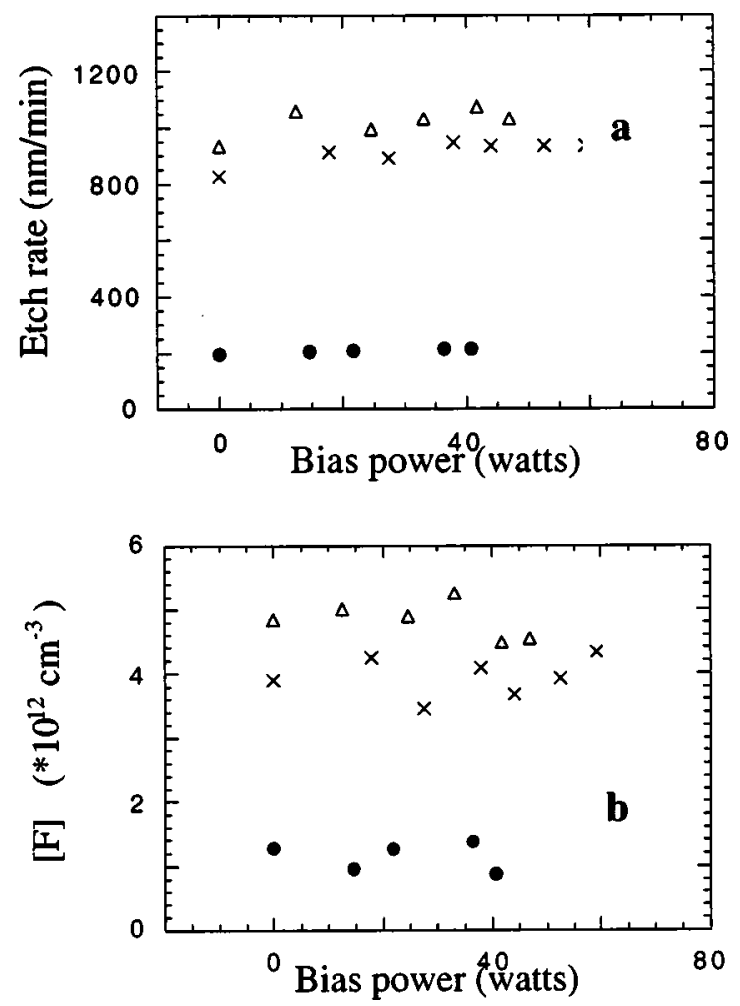

FIG. 4. Etch rate (a) and fluorine concentration (b) as a function of bias power for helicon powers of $430 \mathrm{~W}$ (filled circles), $800 \mathrm{~W}$ (crosses), and $1200 \mathrm{~W}$ (triangles) for a flow of $16.8 \mathrm{sccm} \mathrm{SF}_{6}$.
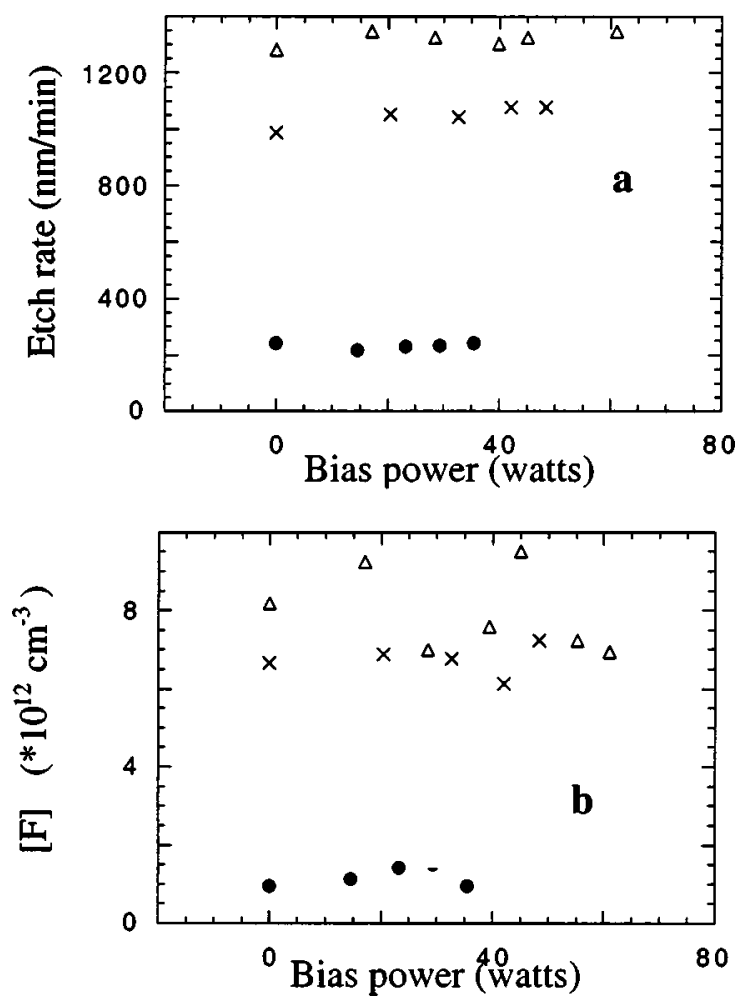

FIG. 5. Etch rate (a) and fluorine concentration (b) as a function of bias power for $\mathrm{rf}$ powers of $430 \mathrm{~W}$ (filled circles), $800 \mathrm{~W}$ (crosses), and $1200 \mathrm{~W}$ (triangles) for a flow of $25 \mathrm{sccm} \mathrm{SF}_{6}$.

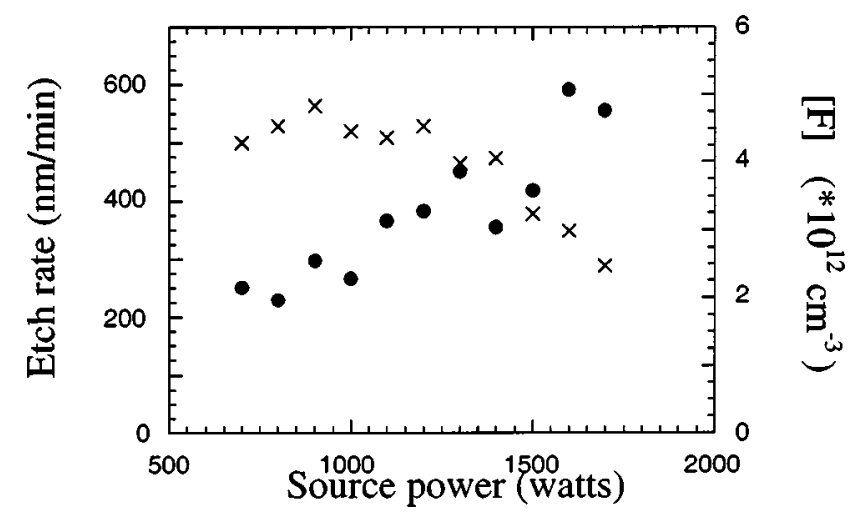

FIG. 6. Etch rate (crosses) and [F] (solid circles) vs source power with no bias and $8 \mathrm{sccm}$.

To further investigate this phenomenon, more detailed measurements were taken of the etch rate and fluorine concentration as a function of source power without bias, and at a constant bias of $60 \mathrm{~W}$ for the three flows. The first is shown in Fig. 6 and displays the etch rate (crosses) and fluorine concentrations (solid circles) as a function of source power at a low flow of $8 \mathrm{sccm}$ without bias (i.e., at low ion energies). A strong suppression of the etch rate was observed at high powers, the etch rate falling by roughly a factor of 2 despite an increase in the fluorine concentration. At low source powers there was essentially no dependence of the etch rate on the source power. These results therefore are consistent with those presented in Fig. 3, and are even more surprising since the etch rate actually decreased at the high source powers.

The effect of increasing the ion energy by applying a bias of $40 \mathrm{~W}$ for varying source power is illustrated in Fig. 7 where the fluorine concentration increased less rapidly than without the bias but the etch rate increased slightly.

While the higher flow rates of Figs. 4 and 5 suggested that the ion energy had essentially no effect on the etch rate, we see that this was not necessarily the case at high source powers and low pressures; here, the importance of ions in the etch reaction was significant and was not restricted to increasing the anisotropy (an increase in anisotropy with increasing bias was observed by Perry $^{3}$ and Petit and

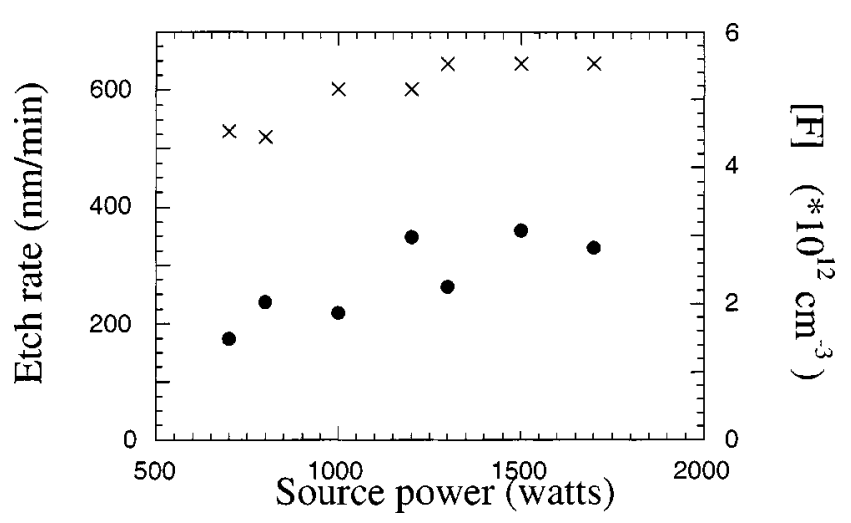

FIG. 7. Etch rate (crosses) and [F] (solid circles) vs source power with $40 \mathrm{~W}$ bias and $8 \mathrm{sccm}$. 


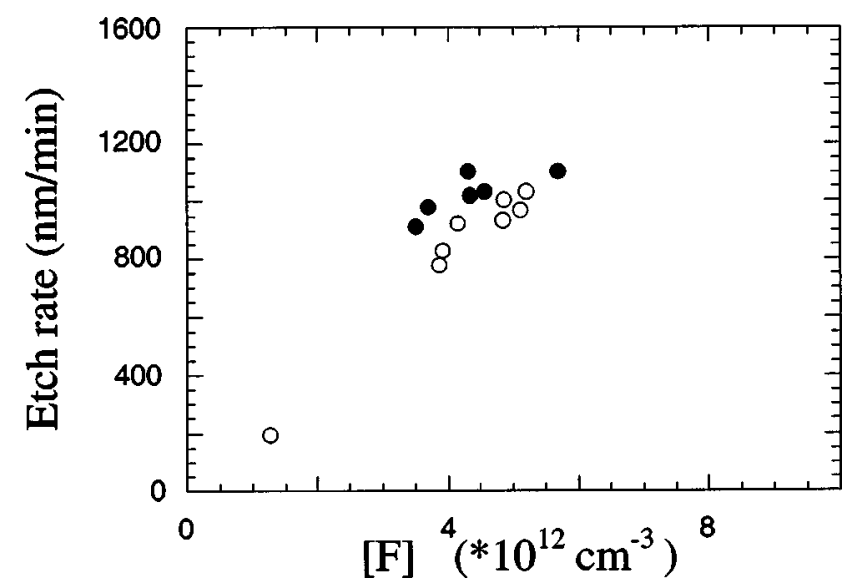

FIG. 8. Etch rate vs $[\mathrm{F}]$ for $16.8 \mathrm{sccm} . \mathrm{SF}_{6}$, zero bias (open circles) and 60 $\mathrm{W}$ bias (filled circles).

Pelletier $\left.^{2}\right)$. At low pressure, the etch rate was scaling with fluorine (as we would expect it to) only in the presence of high energy ions which seemed to be important in overcoming the etch suppression phenomena which was observed in Fig. 6.

The weakening of this suppression at higher flows is demonstrated in Figs. 8 and 9 that are derived from Figs. 4 and 5 by plotting the etch rate directly as a function of fluorine concentration with and without the $60 \mathrm{~W}$ bias at flows of 16.8 and $25.0 \mathrm{sccm}$, respectively.

In the $16.8 \mathrm{sccm}$ case the etch rate was now proportional to the fluorine with the $60 \mathrm{~W}$ bias increasing the etch rate slightly. In the $25.0 \mathrm{sccm}$ case the ions had no significant effect and the etch rate was proportional to the fluorine concentration.

\section{POSSIBLE ETCH MECHANISMS}

For the low flow rate case it is interesting to calculate the fluorine consumed by the etch reaction and to determine its efficiency. Taking a flow of $8 \mathrm{sccm}$, there are $2.2 \times 10^{20} \mathrm{~mol}-$ ecules of $\mathrm{SF}_{6} / \mathrm{min}$ or $3.7 \times 10^{18}$ molecules/s passing through the reactor. If we assume that all the $\mathrm{SF}_{6}$ is dissociated into

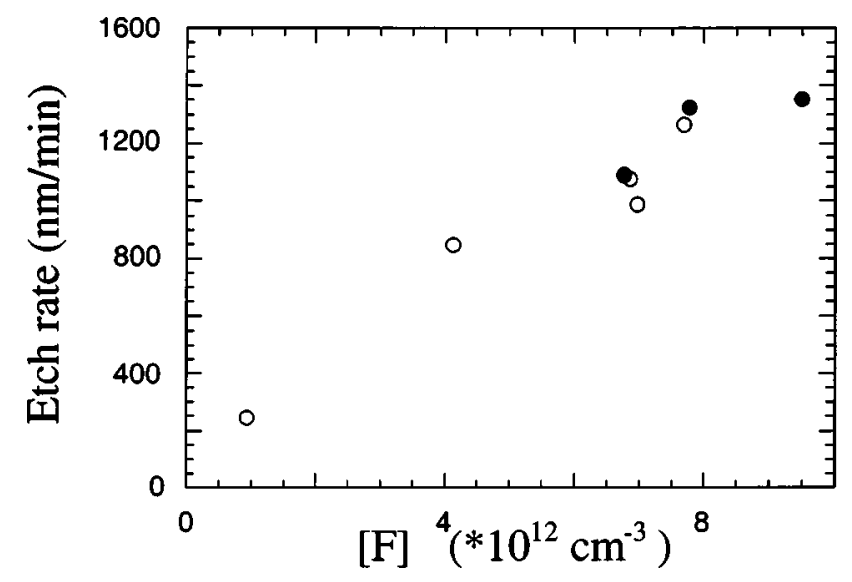

FIG. 9. Etch rate vs [F] for a flow of $25 \mathrm{sccm} . \mathrm{SF}_{6}$, zero bias (open circles) and $60 \mathrm{~W}$ bias (filled circles).
$\mathrm{SF}_{2}$ and 4 atoms of fluorine (Keith Ryan unpublished report 1987) there would be about $1.5 \times 10^{19}$ atoms of fluorine produced per second. Assuming that the silicon eventually leaves the reactor as $\mathrm{SiF}_{4}$ even if it is leaving the exposed surface $\left(68 \mathrm{~cm}^{2}\right)$ of the wafer as $\mathrm{SiF}$ (which optical emission spectroscopy suggests) then for a standard etch rate of 600 $\mathrm{nm} / \mathrm{min}$ [Fig. 3(a)] we would expect $4 \times 10^{18}$ atoms of silicon and $1.6 \times 10^{19}$ atoms of fluorine to be removed per second. This simple calculation strongly suggests that etching the wafer of silicon is by far the dominant pump of fluorine.

Alternately taking the measured fluorine density and etch rate we can deduce what is happening during the etch process. Once again for the $8 \mathrm{sccm}$ case above, for the biased condition and around $1000 \mathrm{~W}$ source power the etch rate is about $650 \mathrm{~nm} / \mathrm{min}$ with a density of $[\mathrm{F}]$ of $3 \times 10^{12} \mathrm{~cm}^{-3}$. The arrival rate of fluorine is $1 / 4 n v$ where $v$ is the mean thermal velocity of the fluorine atoms and is $708 \mathrm{~ms}^{-1}$ for a temperature of $450 \mathrm{~K}$ which we estimate from the wafer temperature: hence there are $5 \times 10^{16} \mathrm{~cm}^{-2}$ fluorine atoms striking the surface every second. The departure rate of silicon is $6.6 \times 10^{16} \mathrm{~cm}^{-2} \mathrm{~s}^{-1}$ strongly suggesting that the etching is proceeding via the detachment of $\mathrm{SiF}$ from the wafer rather than $\mathrm{SiF}_{4}$. It is also not surprising that this is a limit to the etch rate as the most effective use of the atomic fluorine is being made. Any faster rate would have to involve simple physical sputtering, which may be the case for the biased results of Fig. 7.

\section{POSSIBLE CAUSES FOR ETCH RATE SUPPRESSION}

At low flow rates, the etch reaction was not dependent on the concentration of fluorine. This suggested that there might be some other plasma species which was inhibiting the etch reaction and which was increasing with source power. It also had to be most significant at low flow rates since the suppression was observed to decrease at the higher flows. Two candidates presented themselves:

(i) The first was the ion current, which increased as the flow rate was reduced, and as the source power was increased. The mechanism by which the ion current could suppress the etch reaction was unclear. One hypothesis was that the ion current incident on the wafer was sputtering fluorine off the surface before it could react; the problem with this hypothesis is that when the ion energy was increased the sputtering should have become more pronounced, and this was not observed.

(ii) Deposition. While $\mathrm{SF}_{6}$ is not a depositing plasma to the extent of $\mathrm{CF}_{4}$, we cannot discount the effect of such a reaction. It was not immediately clear what the deposit layer would be, but one possibility is that it was an oxide layer forming on the wafer, with the oxygen coming from the etching of the glass source tube. At low flow rates the voltages in the source region would be highest leading to an increase in the sputtering of the glass source tube in the vicinity of the antenna and this could explain the observed behavior. 


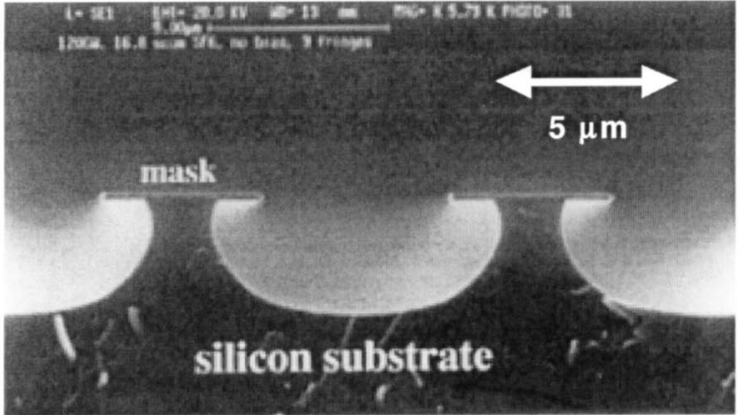

(a)

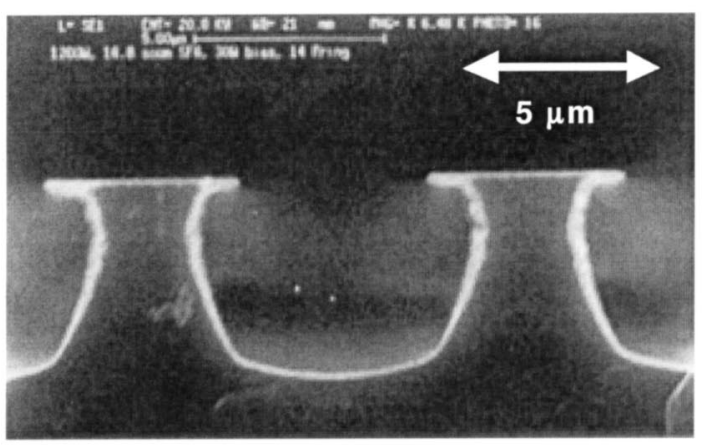

(b)

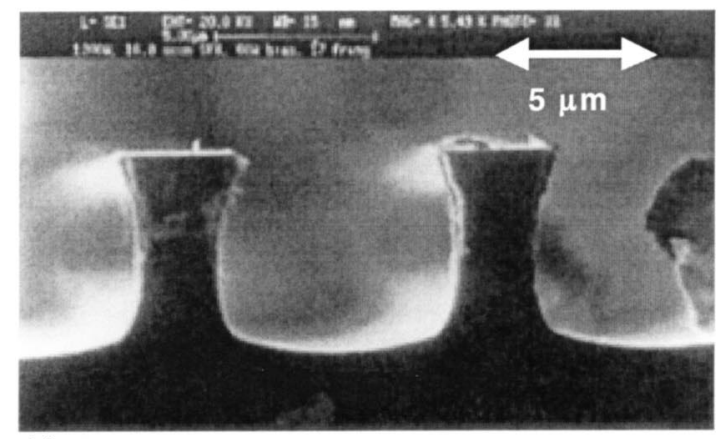

(c)

FIG. 10. Etch profiles at a flow of $16.8 \mathrm{sccm}$ and $1200 \mathrm{~W}$ helicon power with (a) $0 \mathrm{~W}$, (b) $30 \mathrm{~W}$ and (c) $60 \mathrm{~W}$ bias, respectively.

\section{HOW DOES THE ION BOMBARDMENT INCREASE THE ANISOTROPY?}

A contribution by deposition has also been postulated to explain the increasein anisotropy which is observed when the bias power was increased in a $\mathrm{SF}_{6}$ plasma. ${ }^{2,3}$ Experiments were then carried out using patterned wafers and observing the etch profiles using scanning electron microscopy (SEM) photographs. By measuring the amount of lateral and vertical etching the anisotropy could be calculated from

$$
A=1-\frac{V_{\ell}}{V_{V}},
$$

where $V_{\ell}$ and $V_{V}$ are the lateral and vertical etch rates, respectively.

Figures 10(a), 10(b), and 10(c) show the etch profiles at a flow of $16.8 \mathrm{sccm}$ with 0,30 , and $60 \mathrm{~W}$ bias, respectively. All of these photographs were obtained at a helicon power of

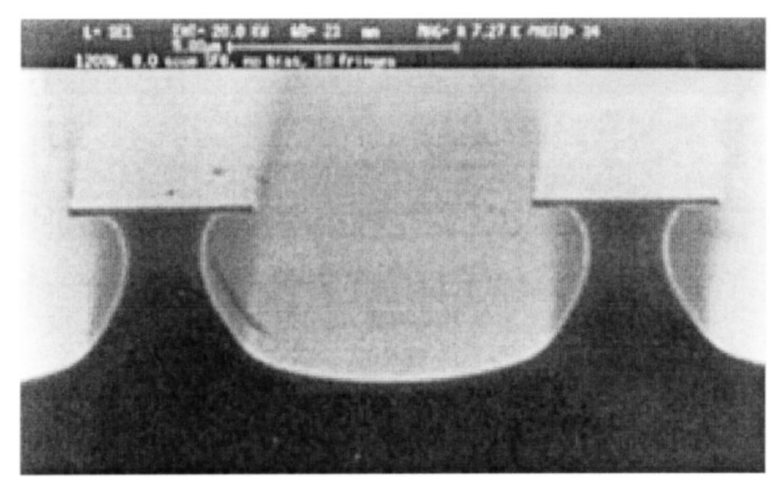

(a)

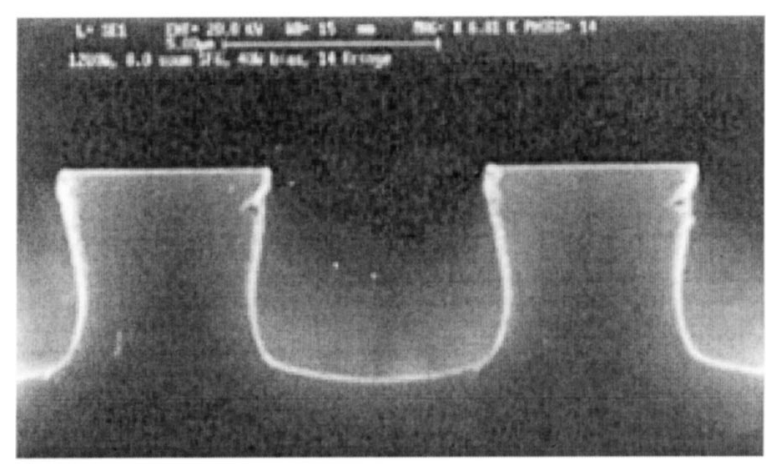

(b)

FIG. 11. Etch profiles at a flow of $8 \mathrm{sccm}$ and $1200 \mathrm{~W}$ helicon power for (a) $0 \mathrm{~W}$ and (b) $40 \mathrm{~W}$ bias.

$1200 \mathrm{~W}$. The anisotropies were $0.58,0.81$, and 0.90 , and an increase in anisotropy with ion energy is evident. The etch times were not the same for these experiments as they were only aimed at showing the anisotropy differences.

The behavior for the low flow of $8 \mathrm{sccm}$ and $1200 \mathrm{~W}$ is shown in Figs. 11(a) and 11(b) for 0 and $40 \mathrm{~W}$ bias yielding anisotropies of 0.71 and 0.92 , respectively. These results strongly suggest that the anisotropy was proportional to the power being deposited by the ions. Perry and Boswell ${ }^{3}$ observed similar behavior, as did Petit and Pelletier. ${ }^{2}$ Both groups found that below a critical pressure perfect anisotropy was achieved; this was not observed in the present experiments.

The SEM photographs also provided a useful validation of the etch rate measurements using interferometry. The etch depths predicted by the number of fringes was consistently less than those obtained with the SEM by $2 \%-3 \%$ and the highest variation was $7 \%$. However, obtaining measurements from the SEM involved a larger error $(5 \%)$ and so this difference was not significant.

Why the higher bias power would lead to higher anisotropy was unclear. When a $\mathrm{CF}_{4}$ plasma is used the polymer is deposited onto all surfaces but as the ion bombardment is only occurring normally to the wafer, the sidewalls are protected. However, $\mathrm{SF}_{6}$ does not in general deposit. This was highlighted by the fact that it etched spontaneously, and by the fact that the etch rate, in general, showed no dependence on bias power, because there was no competition between 


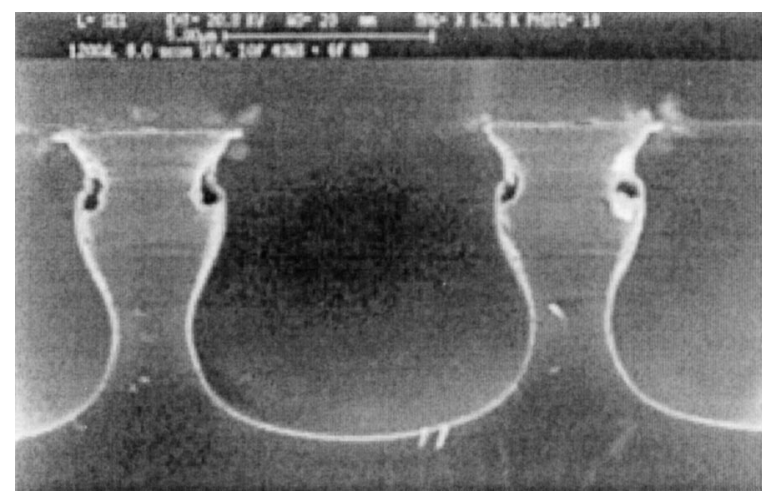

Fig. 12. Etch profile at a flow of $8 \mathrm{sccm}$ and $1200 \mathrm{~W}$ helicon power, first half etch with $40 \mathrm{~W}$ bias and the second half with no bias.

etching and deposition. Therefore it was difficult to understand how the sidewalls were being protected, but two causes could be postulated.

(i) At low ion energies the ion flux was sufficient to modify the fluorine coverage on the bottom surfaces by "sputtering" it back into the gas phase. This would create a gradient in the fluorine concentration between the walls and the floor of the trench and this may have been drawing fluorine off the walls by surface diffusion. ${ }^{3}$ Below a critical pressure the fluorine coverage on the walls had become so low that perfect anisotropy was attained.

(ii) some kind of deposited layer was being formed only in the presence of high energy ions. This seemed unlikely, because if this were occurring then we would expect to see an etch rate decrease as the ion energy went up; this was not observed. Why such a layer would not form without bias is unclear, unless the high energy ions were sputtering the chrome masks and passivating the sidewalls of the profile. Note that this could not explain the suppression in Fig. 6 since that was obtained on double polished wafers. This suggested that if deposition were responsible for protecting the sidewalls, it was occurring by quite a different mechanism then before. It is also quite likely that at low pressures there is severe chemical sputtering of those regions of the source tube adjacent to the helicon antenna. A rough estimate for this source yields a liberation of oxygen equivalent to a few sccm which, if it were in a free state, could significantly alter the etch profiles by oxidizing the sidewalls to form silica.

In an attempt to distinguish between these hypotheses, an etch run was conducted with $40 \mathrm{~W}$ bias applied during the first half of the etch which was then switched off for the second half. If the ions were causing a protective layer to form, then a significant change would be expected when the high energy ions were switched off, because the protective layer deposited in the first half of the run would remain. If, however, some kind of diffusion mechanism was occurring then the etch profile would be constant with depth.

The result is shown in Fig. 12 where a layer can be seen on the sidewalls extending almost halfway down the etched sidewall, although it seems to have detached from the final wall position, possibly due to undercutting by the subsequent "isotropic" etching. Below this halfway point, the profile resembles that obtained from an isotropic etch process, albeit with a certain anisotropy produced by the smaller solid angle at the lower half of the etch. However, this explanation was not entirely satisfactory, because if the oxygen was producing a protective layer on the sidewalls this should also be evident in Fig. 11(a). The reason for the detailed etch behavior at low pressures remains unclear.

\section{PULSED MODE ETCHING}

Although the etch rate has been measured to be proportional to the fluorine concentration, there was still a considerable flux of ions impacting the wafer with an energy of around $20 \mathrm{eV}$. It could then be argued that ion induced etching is still the main process with the ion induced process proceeding, fortuitously, proportionally to the measured fluorine concentration. In order to separate the two effects we have used differing powers for the helicon source and different flow rates but there was no clear delineation. If the power to the helicon source were pulsed then in the afterglow the plasma potential would collapse in a few microseconds in this electronegative plasma, leaving a plasma of room temperature positive and negative ions. Hence, it would be possible to at least reduce the energy of the ions to that of the neutrals and, given that the lifetime of ions in the afterglow is generally much lower than that of reactive species, it may be possible to differentiate between the etch processes if etching continues in the afterglow for a considerable period of time.

Previous work in a rapidly pulsed plasma (greater than 1 $\mathrm{kHz})^{12}$ demonstrated etch rates comparable to those obtained in a continuous plasma, indicating that etching was continuing after extinction of the plasma. However, no study had been made of the fluorine concentration during the pulse, and since the fluorine concentration was extremely important in determining the etch rate, this was a worthwhile area to study. The initial experiments on a pulsed plasma were carried out on a 5-cm-diam prototype helicon reactor and for a constant duty cycle of $20 \%$, the etch rate at pulse periods around $1 \mathrm{~s}$ was one fifth of the continuous value, as expected. As the pulse period was made shorter, the etch rate increased until it finally equaled the continuous etch rate. A model was proposed assuming that the etch rate was proportional to the fluorine concentration and that the fluorine concentration was constant during the on sections and decayed slowly when the plasma was extinguished. ${ }^{1,12}$ Using these assumptions, the results could be modeled quite well using a fitted fluorine lifetime of $50 \mathrm{~ms}$ in the afterglow. Additionally, the model assumed that the fluorine concentration rose essentially instantaneously to a constant value at the beginning of the pulse, as was necessary for the simplicity of the calculation, but it was possible that the behavior was not this simple.

Actinometry could be used during the pulse but it could not be used to measure fluorine concentrations during the off part of a pulse as it relied upon the existence of electrons to excite the atoms, and electrons decayed after plasma extinction on a time scale of microseconds. 


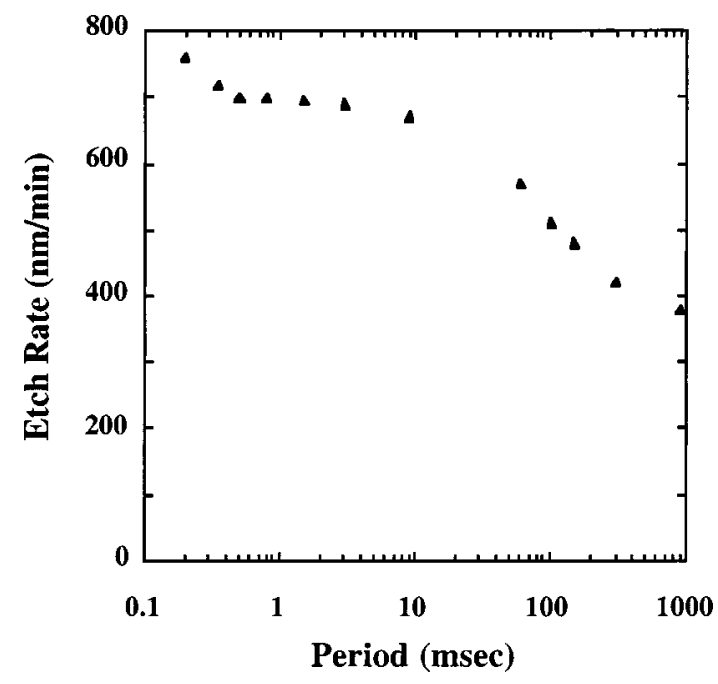

FIG. 13. Etch rate vs pulse duration for $1600 \mathrm{~W}$ helicon power and 16.8 sccm, $33 \%$ duty cycle.

All of the results for the pulsed plasma were obtained at a flow of $16.8 \mathrm{sccm} \mathrm{SF}_{6}$ to allow comparison with the earlier experiments. This medium flow with no bias was used because the results were understood under continuous operation and the etch rate had scaled simply with the fluorine concentration.

The experiments were carried out with a specially modified rf power supply with fast rise and fall times $(\sim 2 \mu \mathrm{s})$ and a fast and complete switch off $\left(P_{\text {off }}=0.1 \% P_{\text {on }}\right.$ which was insufficient to maintain a plasma).

A duty cycle of $33 \%$ was chosen and actinometry was performed using a SPEX 1/2 meter monochromator, since the Monolight scanning monochrometer could not measure intensities on a millisecond time scale. The SPEX was only capable of monitoring a single wavelength at a time but had the advantage of higher temporal and spatial resolution; it was connected to a digital storage oscilloscope and the data transferred to a PC. Care was taken to eliminate background spectral noise; in the case of the argon line this was especially important because the background was contributing up to half of the measured signal. The background "continuum" of the spectrum close to the fluorine and argon lines was measured and subtracted from all data.

Due to the different wavelength response characteristics of the Monolight and the SPEX, a 1600 W continuous plasma was used and the fluorine concentration measured with both. This allowed all measurements taken by the SPEX to be calibrated so that they could be compared to concentrations measured previously with the Monolight.

The etch rates and fluorine concentrations were then measured during the pulsed mode at a power of $1600 \mathrm{~W}$, using pulse durations from $800 \mathrm{~ms}$ to $200 \mu \mathrm{s}$. The average etch rates that resulted are shown in Fig. 13; there is a fairly constant etch rate in the short pulse regime of roughly 700 $\mathrm{nm} \min ^{-1}$, which fell off quite significantly above a pulse duration of $10 \mathrm{~ms}$. The $1600 \mathrm{~W}$ continuous etch rate was measured to be $920 \mathrm{~nm} \mathrm{~min}^{-1}$. If etching were occurring only during the on part of the cycle, then the pulsed etch rate would be a third of $920 \mathrm{~nm} \mathrm{~min}^{-1}$, i.e., $307 \mathrm{~nm} \mathrm{~min}^{-1}$. For the longest pulse period of $1000 \mathrm{~ms}$, the etch rate measured by the IR interferometer showed a value of $378 \mathrm{~nm} \mathrm{~min}^{-1}$, the slightly higher value being partly due to the temperature increase at the beginning of the pulse which was changing the refractive index of the wafer and producing additional fringes which were interpreted as etching. This was not a problem at higher frequencies because the temperature change was too slow.

The expected enhancement at very short pulses was observed with etch rates of up to $770 \mathrm{~nm} \mathrm{~min}{ }^{-1}$. While the etch rate did not attain the continuous rate as was previously observed, ${ }^{1}$ for the very short duration pulses there was a significant rise, a factor of almost 2 , clearly demonstrating that the etch reaction was continuing when the plasma was switched off.

This enhancement was originally interpreted as being caused by the slow decay of the fluorine concentration when the plasma was extinguished (this was also found by Hancock $^{9}$ ). The model proposed assumed that the etch rate (and fluorine concentration) was constant during the on part of the pulse, had an instantaneous rise time and an exponential decay in the off periods. This led to the following expression for the etch rate dependence on pulse period:

$$
E R=1 / t_{\text {period }}\left[E R_{o} t_{\text {on }}+E R_{o} \int_{t_{\text {on }}}^{t_{\text {period }}} \exp (-t / \tau) d t\right]
$$

where $\mathrm{ER}_{0}$ is the continuous etch rate when the pulse is on and $\tau$ is the fluorine lifetime after switch off.

It is important to realize that this model assumed that the etch rate was constant during the on period and was equal to the continuous etch rate. The results of Fig. 13 are not in very good agreement with this model, which would predict that the etch rate at short periods would be $920 \mathrm{~nm} \mathrm{~min}^{-1}$ (that of the continuous plasma) rather than the highest measured rate of $790 \mathrm{~nm} \mathrm{~min}{ }^{-1}$. Clearly, this assumption is incorrect and a measurement of the etch rate during the pulse would clear up the problem. This is not possible with the present apparatus as only time average etch rates could be measured. However, using time resolved actinometry measurements it is possible to display the evolution of fluorine concentration with time. Figures 14(a)-14(d) show that the fluorine flux of four different pulse frequencies was neither constant nor had an instantaneous rise time. As it has been shown previously that the etch rate is proportional to the fluorine concentration it is reasonable to assume that the etch rate follows the temporal evolution of the fluorine concentration and hence is not constant during the pulse.

A peak in the fluorine concentration during the early part of the pulse was quite marked at very short pulse lengths and was interpreted as being due to a spike in the source power immediately after switch on. Using an oscilloscope and a $-56 \mathrm{~dB}$ directional coupler, an initial peak in the rf power of more than $3000 \mathrm{~W}$ was measured, with a lifetime of roughly $120 \mu \mathrm{s}$. The fluorine peak in Fig. 14(c) showed a lifetime of 


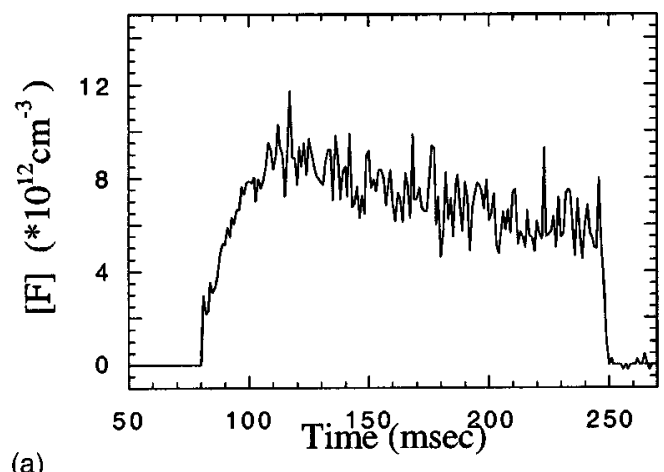

(a)

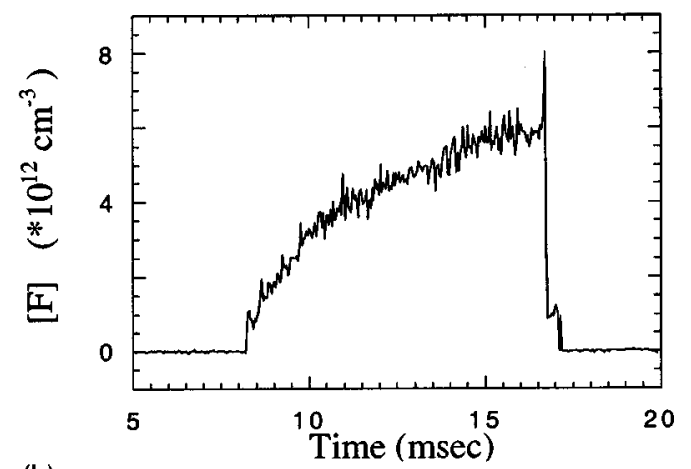

(b)

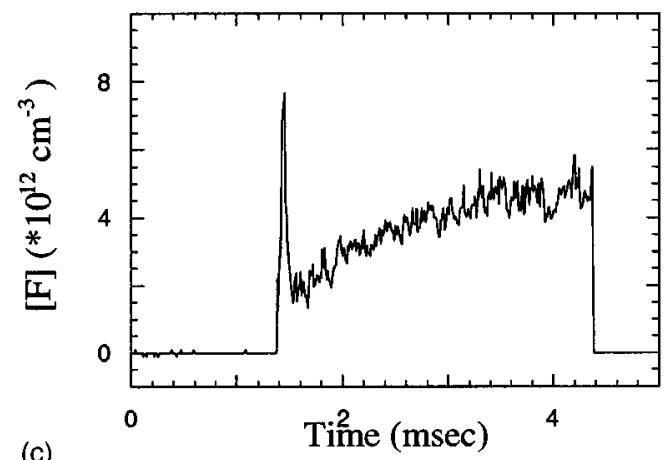

(c)

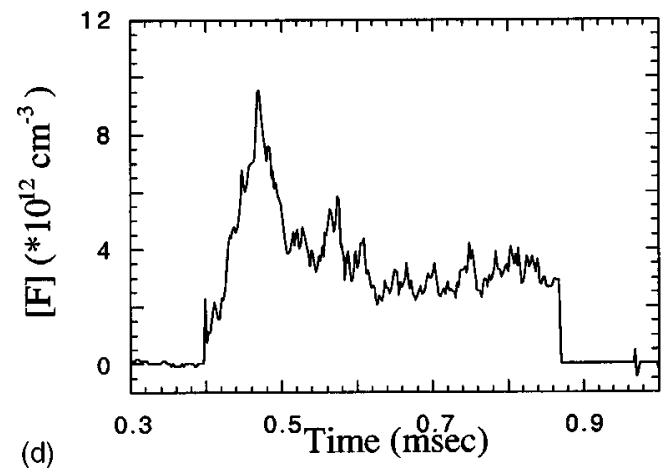

FIG. 14. (a) Fluorine concentration for pulse frequency of : (a) $2 \mathrm{~Hz}$, (b) 40 $\mathrm{Hz}$, (c) $111 \mathrm{~Hz}$, (d) $718 \mathrm{~Hz}$.

$100 \mu$ s and so this high power burst seemed the most likely cause.

It has been observed by Perry, Vender, and Boswell ${ }^{13}$ that there was a high energy spike in both the electron and ion energy distribution functions just after turn on which could

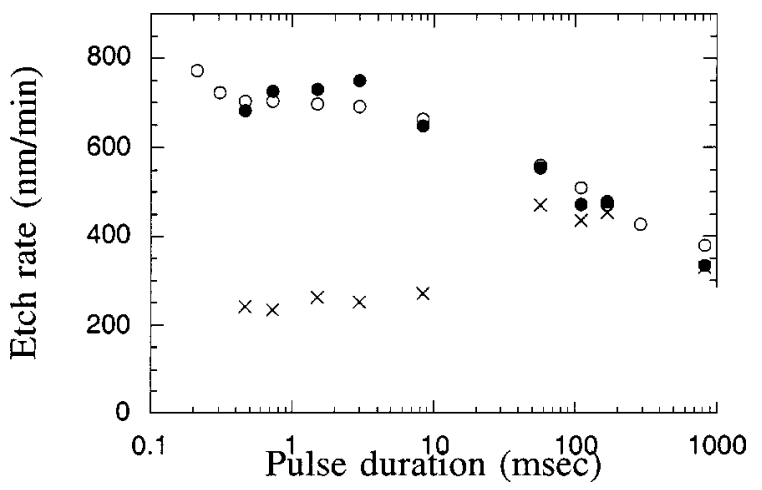

FIG. 15. Pulsed etch rate (open circles), modeled etch rate with instant decay (crosses), and with $10 \mathrm{~ms}$ decay (filled circles).

lead to increased dissociation. A consequent increase in the fluorine concentration could contribute to the increase in etch rate at the shortest pulse length measured, because the peak was now dominating the fluorine levels.

The change in concentration with pulse length was possibly caused by competition between formation of fluorine by dissociation of the etch gas, and the consumption of fluorine by the silicon wafer and by losses to the walls.

The time average of the fluorine concentration during the on period can be obtained by integrating the measured temporal variation of $[\mathrm{F}]$ obtained by actinometry. Previous results showed that at this flow, the etch rate was proportional to the fluorine concentration, and so it was possible to calculate the etch rate that this average $[\mathrm{F}]$ concentration would produce. The etch rates that were predicted with no fluorine at all in the off times are shown in Fig. 15. Clearly there was no correlation between these and the etch rates that were measured at the short pulse lengths. The best fit to the experimental data was found by assuming that etching continues in the afterglow and decreased with a time constant of 10 ms.

It is now important to discuss the possible reasons for this result.

One possibility is that the desorption of the etch product has a time constant and it is this time constant we are measuring.

The second possibility, the one that we prefer, is that the atomic fluorine continues to etch the silicon with a time constant of $10 \mathrm{~ms}$. This result was extremely interesting because the time constant was an order of magnitude shorter than the residence time of the reactor (about $100 \mathrm{~ms}$ considering only the turbo pump), indicating that this type of pumping gas was not the primary loss mechanism for fluorine, contrasting to Hancock's ${ }^{9}$ results that showed the fluorine lifetime to be similar to the pump out time of the reactor. However, if we consider the removal of fluorine by etching in the continuous plasma we arrive at a residence time of $10 \mathrm{~ms}$, surprisingly close to the etch lifetime in the afterglow.

It is also useful to calculate the consumption of fluorine by etching of the $\mathrm{SiO}_{2}$ in the glass walls of the plasma source. The total length of the $1-\mathrm{cm}$-wide strip helicon antenna on the glass is about $120 \mathrm{~cm}$ and it will have about 2 
$\mathrm{kV}$ of rf between the "hot" end and the earther end. This will produce a negative bias charge of about $-V_{\text {rf }}$ to form on the inside of the glass and a sheath will form around the glass adjacent to and following the antenna wires. Reactive ions will be accelerated in this sheath in the reactive atmosphere of the dissociated $\mathrm{SF}_{6}$ and will etch the glass walls next to the antenna strips. We estimate the surface being etched as approximately $100 \mathrm{~cm}^{2}$ allowing for the voltage variation along the antenna and that the etched area will be somewhat larger than the actual area presented by the antenna. Previous experiments in this reactor under similar conditions showed that $\mathrm{SiO}_{2}$ etched at about $0.5 \mu \mathrm{m} / \mathrm{min}$. If the fluorine leaves as $\mathrm{SiF}_{4}$, then we obtain a loss of fluorine of $8 \times 10^{18} \mathrm{~s}^{-1}$, which is about half that of the removal rate of fluorine by etching of the silicon wafer. This etching will result in a residence or lifetime for the fluorine of about $20 \mathrm{~ms}$.

With these estimates it is now possible to understand the rise times of the fluorine line in Fig. 2: in both cases, with and without the silicon wafer, the rise time is between 10 and $20 \mathrm{~ms}$ which correlates very well with the residence times calculated above for fluorine.

Alternatively, some other effect was limiting the lifetime of fluorine in the absence of a plasma, and recombination on the walls has been suggested as a possible cause. The recombination time of fluorine on (clean) Pyrex has been measured by Nordine and LeGrange ${ }^{14}$ to be $50 \mathrm{~ms}$.

\section{SUMMARY AND DISCUSSION}

In this experimental study of etching of silicon by $\mathrm{SF}_{6}$ in a high density helicon reactor it was found that, in general, the etch rate of silicon was proportional to the fluorine concentration; at least this was so at high flow rates. Applying a bias to the substrate did not increase the etch rate at high flow rates.

At low flow rates the application of the bias appeared to remove some form of deposition. Although the provenance of the material forming the deposited layer is unknown, it may be an oxide created by oxygen liberated by the etching of the Pyrex source tube in regions close to the helicon antenna. A simple calculation of the reactive sputtering (or etching) induced by the rf voltage on the antenna shows that the equivalent of a few sccm of oxygen may be liberated. An advantageous consequence is that the anisotropy of the etch increased as the bias power was increased. The details of this phenomenon remain unclear.

The etch rate being independent of the substrate bias at high flow rates implies that atomic fluorine is the main active species in the process. By taking a thermal flux of the measured atomic fluorine concentration to the surface of the wafer and the measured etch rate it appears that $\mathrm{SiF}$ is the volatile compound leaving the surface. A calculation of the total fluorine entering the reactor and the total silicon leaving strongly suggests that the silicon is being pumped away as $\mathrm{SiF}_{4}$ and that the $\mathrm{SF}_{6}$ is dissociated into $\mathrm{SF}_{2}$ and four atoms of fluorine.

At high flow rates, the linearity of the etch rate with atomic fluorine concentration, its independence on the bias power, and the continuation of the etch in the afterglow strongly suggest that the silicon is being etched by atomic fluorine and is not being enhanced by ion bombardment. There have been a number of studies using "hyperthermal" beams of neutral fluorine (and other species). ${ }^{15,16}$ which show high etch rates and efficient use of the available fluorine. These experiments have no ions involved and the results of Giapis ${ }^{15}$ for etching of silicon by atomic fluorine are very close to those presented here for the high flow rates.

In an early article, Flamm, Donnelly, and Mucha ${ }^{17}$ present results showing an etch rate that depended on the system temperature and was considerably lower than that measured here. It would seem that it is not simply the temperature of the substrate which plays a role in the etching and the "temperature" of the arriving fluorine needs to be considered. For the present experiments, it is possible that the fluorine is considerably hotter than room temperature but many experiments on this an other similar systems do seem to suggest that the highest temperature of gas phase species would be below $500{ }^{\circ} \mathrm{C}$.

Pulsing the plasma showed that the etching results can be well modeled by assuming etching is proceeding in the afterglow with a time constant of $10 \mathrm{~ms}$. This time is well correlated to estimates of the residence time of fluorine in the reactor strongly suggesting that, in the absence of ions, it is the atomic fluorine that is responsible for the etching.

An alternate explanation would be that the ions prepare the surface in some manner during the time the plasma is on, perhaps by allowing a thin layer of fluorinated silicon to form. The etch process would then proceed via thermal desorption of the weakly bound etch products. It could also be that the ion bombardment during the plasma, even with no bias, is sufficient to aid in the desorption of the etch products. When the plasma is switched off, this film, which would be weakly bound to the surface, could continue to evaporate with a time constant of $10 \mathrm{~ms}$. It is possible that the effects of the ion bombardment during the plasma pulse (surface cleaning, enhanced desorption, etc.) are sufficiently long lived to appear to still operated in the afterglow, even when the sheath has collapsed.

An absolute explanation of all the phenomena presented in this article is not possible at present. The main aim of the authors has been to present the data and the analysis along with their opinion of what physical phenomena may be important.

${ }^{1}$ R. W. Boswell and D. Henry, Appl. Phys. Lett. 47, 1095 (1985).

${ }^{2}$ B. Petit and J. Pelletier, Jpn. J. Appl. Phys., Part 1 26, 825 (1987).

${ }^{3}$ A. J. Perry and R. W. Boswell, Appl. Phys. Lett. 55, 148 (1989).

${ }^{4}$ J. Ding, J.-S. Jenq, G.-H. Kim, H. L. Maynard, J. S. Hamers, N. Hershkowitz, and J. W. Taylor, J. Vac. Sci. Technol. A 11, 1283 (1993).

${ }^{5}$ H. F. Winters and J. W. Coburn, J. Vac. Sci. Technol. 16, 391 (1979).

${ }^{6}$ R. W. Boswell, Phys. Lett. A 33, 457 (1970).

${ }^{7}$ R. d'Agostino, F. Cramarossa, V. Colaprico, and R. d'Ettole, J. Appl. Phys. 54, 1284 (1983).

${ }^{8}$ J.-S. Jenq, J. Ding, J. W. Taylor, and N. Hershkowitz, Plasma Sources Sci. Technol. 3, 154 (1994).

${ }^{9}$ G. Hancock, J. P. Sucksmith, and M. J. Toogood, J. Phys. Chem. 94, 3269 (1990). 
${ }^{10}$ R. A. Gottscho, C. W. Jurgensen, and D. J. Vitkavage, J. Vac. Sci. Technol. B 10, 2133 (1992).

${ }^{11}$ R. A. Gottscho, J. Vac. Sci. Technol. B 11, 1884 (1993).

${ }^{12}$ R. W. Boswell and R. K. Porteous, J. Appl. Phys. 62, 3129 (1987).

${ }^{13}$ A. J. Perry, D. Vender, and R. W. Boswell, J. Vac. Sci. Technol. B 9, 310 (1991).

${ }^{14}$ P. C. Nordine and J. D. LeGrange, AIAA J. 14, 644 (1976).
${ }^{15}$ K. P. Giapis, T. A. Moore, and T. K. Minton, J. Vac. Sci. Technol. A 13, 965 (1995).

${ }^{16}$ P. R. Larson, K. A. Copeland, G. Dharmasena, R. A. Lasell, M. Keil, and M. B. Johnson, J. Vac. Sci. Technol. B 18, 307 (2000).

${ }^{17}$ D. L. Flamm, V. M. Donnelly, and J. A. Mucha, J. Appl. Phys. 52, 3633 (1981). 